\title{
Relationship between Occupational Stress and Work-related Musculoskeletal Disorders in Korean Male Firefighters
}

\author{
Min Gi Kim ${ }^{1}$ Kyoo-Sang Kim²*, Jae-Hong Ryoo ${ }^{3}$ and Seung-Won Yoo ${ }^{2}$
}

\begin{abstract}
Objectives: A growing body of literature has documented that job stress is associated with the development of work-related musculoskeletal disorders (WMSDs). However, the association of WMSDs with job stress has not yet been fully studied in Korean male firefighters. The purpose of this study was to determine the status of WMSDs in almost all Korean male firefighters and to clarify the effect of job stress on the occurrence of WMSDs.

Methods: The study design was cross-sectional, and 21,466 firefighters were recruited. The study design included a structured questionnaire to assess general characteristics, the Korean Occupational Stress Scale (optional KOSS-26), Center for Epidemiologic Studies-Depression Scale (CES-D), and WMSDs. The chi-square test, and univariate and multivariate logistic regression analyses were used to look for a correlation between general characteristics and job stress, and the occurrence of WMSD.
\end{abstract}

Results: Back pain is the most common WMSD. Among the job stress subgroup, physical environment, job demands, organizational system, occupational climate, lack of reward and job insecurity were related to the occurrence of WMSDs. However, insufficient job control and interpersonal conflict were not related to the occurrence of WMSDs.

Conclusion: Job stress was related to the occurrence of WMSDs in Korean male firefighters. To reduce the occurrence of WMSDs, a job stress management program may be required.

Keywords: Work-related musculoskeletal disorder, Firefighter, Job stress

\section{Introduction}

In South Korea, firefighters are public employees who prevent and suppress fire, perform emergency rescues, and respond to disasters in a recovery role. They are also exposed to physical dangers including heat, noise, poisonous gases, smoke, carbon monoxide, and diesel fumes [1]. Moreover, they are exposed to traumatic accidents and mental diseases [2,3]. The rate of post-traumatic stress disorder [2-5], mortality by cardiovascular disease [6], musculoskeletal disease [7], and oxidative DNA damage [8] are higher in firefighters than general population. The relationship between these diseases and job stress

\footnotetext{
* Correspondence: kobawoo@kosha.net

${ }^{2}$ Center for Occupational Disease Research, Occupational Safety and Health Research Institute, Korea Occupational Safety and Health Agency, Incheon, South Korea

Full list of author information is available at the end of the article
}

and shift work [9], overtime work, a heavy workload $[10,11]$, discord at work, low social support, role conflicts, and low self-esteem [12] have been studied in firefighters. In Korean firefighters the turnover decision factor [13], job satisfaction [14], occupational climate [15], conduct of business [16], and safety-related accident factors [17] have been studied.

Because of heavy equipment, fire-fighting requires excessive energy and awkward postures, so work-related musculoskeletal disorders(WMSDs) can easily develop. According to United States statistics from 2007, musculoskeletal system diseases like sprains of the muscle or ligament were over $40 \%$ of the problems that developed in fire fighting [18]. From 2007, work-related accidents were reported for 279 people among 30,630 Korean firefighters. However, there is no information about WMSDs in Korea [18]. 
Only one study has addressed the association between WMSDs and job stress in Korean firefighters [19], but it did not adequately confirm the relationship between job stress and WMSDs. Also, the study population was small. The purpose of this study was to determine the status of WMSDs in almost all male Korean firefighters and to understand the effect of job stress on the occurrence of WMSDs.

\section{Materials and Methods \\ Study subjects}

Between early July 2007 and the end of November 2007, structured questionnaires were distributed to 30,601 Korean firefighters. In total, 25,610 (83.6\%) of the firefighters responded to the questionnaire. The 1292 female fighters composed only a small portion (4.9\%) of the total, so we excluded female firefighter cases. Among those who respond to the questionnaire, only 21,466 (83.8\%) firefighters completed the questionnaire, so they were selected as the final subjects.

\section{The method of study and definition}

The structured questionnaires had 4 sections; general characteristic factors; work-related job stress factors, depression factors, and WMSDs. The general characteristic factors comprised age, marital status, drinking habits, smoking habits, sports-playing habits, level of education, and work department (Firefighting, Rescue, Emergency Medical Services, or Other). The level of education was defined as at least 16 years or less than that, based on the time required for university graduation. The pay grade was based on the current rank system, which was broken down into firefighter, senior fire sergeant, fire sergeant, fire lieutenant, and a position higher than fire lieutenant. In addition, we measured drinking habits using the Alcohol Use Disorders Identification Test (AUDIT) questionnaire [20]. Anyone who had 8 points or more in the AUDIT questionnaire was defined as a problematic heavy drinker [21]. Anyone who did not smoke for a week before the survey or who did not smoke at all was defined as a non-smoker.

The job stress factors were measured by the short form of the Korean Occupational Stress Scale(KOSS-26) [22]. The KOSS-26 inquires about the physical environment, job demands, insufficient job control, interpersonal conflict, job insecurity, organizational system, lack of reward, and occupational climate. The score of each sub-area of job stress survey was converted into units 100 point scale. In this study, the high-risk group was defined as higher than the 75th percentile, and the lowrisk group as lower than the 75th percentile in each subclass of job stress. The depression factors were measured by the Center for Epidemiologic Studies-Depression Scale (CES-D). Anyone who had 21 points or more on the CES-D questionnaire was defined as depressed [23]. Work-related musculoskeletal disorders were measured by the Korean NIOSH Symptom Survey [24] which consists of questions regarding the presence of work-related symptoms in any of 6 body regions (neck, shoulders, arms, hands/wrists, lower back, and legs/feet) in the prior year, and symptom severity (frequency, duration, and intensity). The frequency of the symptoms was rated on a 5-point scale ranging from 1 (every 6 months) to 5 (daily). The duration of the symptoms was rated on a 5-point scale ranging from 1 (less than 1 day) to 5 (6 months or greater). The intensity of the symptoms was rated on a 5-point scale ranging from 1 (mild pain) to 5 (very severe pain). WMSD cases were defined as symptoms that had occurred at least once a month or lasted at least one week in the past year and with at least moderate pain intensity [25].

\section{Statistical methods}

The reliability coefficient of the job stress questionnaire was 0.799 and that of the CES-D was 0.875 . The chi-squared test was used for the general characteristics of the firefighters and job stress. Uni-variate and multivariate logistic regression analysis were used to look for a correlation between general characteristics and job stress, and the occurrence of WMSD. Univariate logistic regression analysis was performed with each job stress subtype as an independent variable (Model I). Multivariate logistic regression analysis was performed with age, tenure, exercise, smoking, drinking, marital status, job title and job class as adjusted factors (Model II). Model III added depression to Model II as an adjusted factor. Statistical analyses were performed using the SPSS 17.0 for Windows software package (SPSS, Chicago, IL). All reported $p$ values were two-tailed and those with results $<0.05$ were considered to be statistically significant.

\section{Results}

\section{General characteristics}

The prevalence of WMSD was $11.0 \%$ (2,362 persons). The age of non-WMSD firefighters $(39.6 \pm 7.4)$ was statistically higher than the WMSD firefighters $(39.0 \pm 6.6)$. Non-WMSD firefighter work periods were statistically higher than those of the WMSD group. Statistical differences in marriage, education, problem drinking, exercise, main job, job class, and depression were observed between the two groups. The depression group was $17.7 \%$ (3,807 persons) (Table 1$)$.

\section{The ratio of complaints of WMSD}

The most common pain site was the back with 1,294 (6.0\%) complaints, followed by the neck with 724 (3.4\%) complaints. There were fewer complaints about the foot, shoulder, hand, and arm (Table 2). 
Table 1 General characteristics of subjects according to musculoskeletal symptoms

\begin{tabular}{|c|c|c|c|c|c|c|}
\hline \multirow[t]{3}{*}{ General characteristics } & & \multirow{2}{*}{\multicolumn{2}{|c|}{$\begin{array}{r}\text { Symptom (+) } \\
n=2,362\end{array}$}} & \multirow{2}{*}{\multicolumn{2}{|c|}{$\begin{array}{r}\text { Symptom (-) } \\
n=19,104\end{array}$}} & \multirow[t]{3}{*}{ p-value } \\
\hline & & & & & & \\
\hline & & Mean & SD & Mean & SD & \\
\hline Age (years) & & 39.0 & 6.6 & 39.6 & 7.4 & $<0.01$ \\
\hline \multirow[t]{2}{*}{ Tenure (years) } & & 11.1 & 6.7 & 11.7 & 7.5 & $<0.01$ \\
\hline & & $n$ & $\%$ & N & $\%$ & \\
\hline \multirow[t]{2}{*}{ Marriage } & Married & 2,003 & 11.2 & 15,807 & 88.8 & $<0.01$ \\
\hline & Single & 359 & 9.8 & 3,228 & 90.2 & \\
\hline \multirow[t]{2}{*}{ Education (years) } & $<16$ & 894 & 10.9 & 7,295 & 89.1 & $<0.01$ \\
\hline & $\geqq 16$ & 1,468 & 11.1 & 11,809 & 89.9 & \\
\hline \multirow[t]{2}{*}{ Problem drinking } & Yes & 881 & 10.1 & 7,875 & 89.9 & 0.02 \\
\hline & No & 1,481 & 11.7 & 11,229 & 88.3 & \\
\hline \multirow[t]{2}{*}{ Exercise } & Yes & 2,103 & 10.9 & 17,137 & 89.1 & $<0.01$ \\
\hline & No & 259 & 11.6 & 1,967 & 88.4 & \\
\hline \multirow[t]{2}{*}{ Smoking } & Yes & 1,000 & 11.6 & 7,612 & 88.4 & $<0.01$ \\
\hline & No & 1,362 & 10.6 & 11,492 & 89.4 & \\
\hline \multirow[t]{4}{*}{ Main job } & Firefighting & 1,113 & 10.5 & 9,476 & 89.5 & $<0.01$ \\
\hline & Rescue & 597 & 16.9 & 2,932 & 83.1 & \\
\hline & Emergency medical service & 254 & 12.9 & 1,718 & 87.1 & \\
\hline & Others & 398 & 7.4 & 4,978 & 92.6 & \\
\hline \multirow[t]{4}{*}{ Job class } & Firefighter & 517 & 10.7 & 4,334 & 89.3 & $<0.01$ \\
\hline & Senior fire sergeant & 890 & 12.8 & 6,085 & 87.2 & \\
\hline & Fire sergeant & 727 & 11.5 & 5,588 & 88.5 & \\
\hline & Fire lieutenant or higher & 228 & 6.9 & 3,077 & 93.1 & \\
\hline \multirow[t]{2}{*}{ Depression(CES-D) * } & $<21$ & 1,608 & 16.0 & 16,051 & 84.0 & $<0.01$ \\
\hline & $\geqq 21$ & 754 & 31.9 & 3,053 & 68.1 & \\
\hline
\end{tabular}

*: Center for Epidemiologic Studies-Depression Scale (CES-D).

Logistic regression analysis of WMSDs according to job stress adjusted for the psychosocial component

Among those with job stress, only insufficient job control did not show statistical significance (Table 3). By adjusting the general characteristics, we found that physical environment, at odds ratio of 2.31 (95\% CI, 2.03 - 2.62); job demand, at 1.55 (95\% CI, 1.38 - 1.74); interpersonal conflict, at 1.15 (95\% CI, 1.03 - 1.29); job insecurity, at 1.13 (95\% CI, 1.02 - 1.25); organizational system, at 1.24 (95\% CI, 1.10 - 1.38), and occupational climate, at 1.33 (95\% CI, 1.19

Table 2 Musculoskeletal pain locations in study subjects

\begin{tabular}{lcc}
\hline Region & $\mathbf{n}^{*}$ & $\%$ \\
\hline Shoulder & 462 & 2.2 \\
Neck & 724 & 3.4 \\
Lumbar & 1,294 & 6.0 \\
Hand & 225 & 1.0 \\
Foot & 714 & 3.3 \\
Arm & 162 & 0.8 \\
\hline
\end{tabular}

"multiple choice. to 1.49) were statistically significant (Model II). Adjusted for depression and general characteristics in the multivariate analysis produced 2.22 (95\% CI,1.96 - 2.53) for the physical environment; 1.52 (95\% CI,1.35 - 1.70) for job demand; 1.14 (95\% CI,1.01 - 1.28) for job insecurity; 1.37 (95\% CI,1.21 - 1.58) for organizational system; 1.15 (95\% CI,1.01 - 1.31) for lack of reward; 1.24 (95\% CI,1.11 - 1.40) for occupational climate (Model III) (Table 4).

\section{Discussion}

As with the previous study [25], back pain was the most common WMSD in firefighters. This study shows that job stress may have an association with WMSDs in firefighters. Among the job stress subgroup, physical environment, job demand, job insecurity, lack of reward, and occupational climate were associated with WMSDs.

Because fire-fighting is urgent and unpredictable, it is known to generate extreme psychological and physical burdens in the line of duty [26]. When rescuing victims and extinguishing fires, WMSDs can arise due to the unbalanced body positions resulting from the use of heavy 
Table 3 Relationship between job stress and musculoskeletal symptom

\begin{tabular}{|c|c|c|c|c|}
\hline & \multicolumn{4}{|c|}{ Symptom(+) } \\
\hline & Total(n) & $\mathrm{n}$ & Frequency(\%) & $\mathrm{p}$-value \\
\hline Physical environment & & & & $<0.001$ \\
\hline High risk & 10,825 & 1,700 & 15.70 & \\
\hline Low risk & 10,641 & 662 & 6.22 & \\
\hline Job demand & & & & $<0.001$ \\
\hline High risk & 8,822 & 1,444 & 16.37 & \\
\hline Low risk & 12,644 & 918 & 7.26 & \\
\hline Insufficient job control & & & & 0.027 \\
\hline High risk & 9,048 & 1,046 & 11.56 & \\
\hline Low risk & 12,418 & 1,316 & 10.60 & \\
\hline Interpersonal conflict & & & & $<0.001$ \\
\hline High risk & 8,529 & 1,137 & 13.33 & \\
\hline Low risk & 12,937 & 1,225 & 9.47 & \\
\hline Job insecurity & & & & $<0.001$ \\
\hline High risk & 5,644 & 894 & 15.84 & \\
\hline Low risk & 15,822 & 1,468 & 9.28 & \\
\hline Organizational system & & & & $<0.001$ \\
\hline High risk & 6,807 & 1,097 & 16.12 & \\
\hline Low risk & 14,659 & 1,265 & 8.63 & \\
\hline Lack of reward & & & & $<0.001$ \\
\hline High risk & 5,683 & 897 & 15.78 & \\
\hline Low risk & 15,783 & 1,465 & 9.28 & \\
\hline Occupational climate & & & & $<0.001$ \\
\hline High risk & 6,265 & 1,022 & 16.31 & \\
\hline Low risk & 15,201 & 1,340 & 8.82 & \\
\hline Total job stress & & & & $<0.001$ \\
\hline High risk & 5,407 & 1,280 & 23.67 & \\
\hline Low risk & 16,059 & 1,082 & & \\
\hline
\end{tabular}

fire protection equipment [19]. Back pain is caused by various factors including poor posture, degenerative changes, and psychological states. The principal factor is a biomechanical factor because of mechanical stress, particularly heavy weight-handling work. Excessive force is put on the lower back when firefighters use heavy equipment [25]. Work situations that cause back pain for firefighters include operating a charged hose inside a building (odds ratio $(\mathrm{OR})=3.26$ ), climbing ladders $(\mathrm{OR}=3.18)$, breaking windows $(\mathrm{OR}=4.45)$, cutting structures $(\mathrm{OR}=6.47)$, looking for hidden fires $(\mathrm{OR}=$ 4.32), and lifting objects $\geq 18 \mathrm{~kg}(\mathrm{OR}=3.07)$ [27]. The risk gradually increased as the fire fighter moved away from the firehouse $(\mathrm{OR}=0.10)$ and closer to the site of the fire $(\mathrm{OR}=3.91)$ [27].

WMSD is a multi-factorial disorder related to various demographic and general features and work-related characteristics [28,29]. Social-demographic features, work-related characteristics, health-related behaviors, and job stress can all affect social psychological health levels [30]. Old age, unemployment, past musculoskeletal pain, and shift work are factors that extend the symptoms [31]. There is a hypothesis that muscle strain increases if job-related psychological burdens increase due to job stress, and job stress increases awareness of musculoskeletal symptoms or reduces the capability to manage the symptoms $[25,32,33]$. Unemployment experience, monthly income, lack of sleep, and drinking status acted as major cause of stress [34]. Job insecurity, interpersonal conflicts, the physical environment, and organization systems had negative impacts on the level of mental stress of firefighters [35]. The physical environment had a greater effect on field service workers than office workers [36]. The total job stress of firefighters was similar to that of general workers, but the physical environment factor was higher with firefighters than with general workers. Job insecurity and lack of rewards had somewhat less impact on firefighters than general workers [6]. As pointed out previously, firefighting is dangerous and requires best practices in handling bodily burdens. A lack of reward was associated with WMSDs and the same result has been observed in previous studies [25,37], and in office workers [38].

However, insufficient job control does not show as much correlation with WMSDs as a consistent lack of reward [25]. In the present study, a correlation could not be found. The organizational system score evaluates the organization of political tactics, operating systems, organizational resources, and reasonable communication within the community [22]. In subway workers, the organization system score was statistically significantly higher (bad) than in firefighters [36]. The authors believe that South Korea's authoritarian and vertical organization system and lack of communication would tend to increase the development of WMSDs.

Depression is known to be related to job stress [39] and Kim et al. [40] have noted that the job insecurity and depression level is high in emotional labor workers. Depression is a major factor of absence and labor injuries [41], and it is known as an independent precursor to neck and lumbar pain [42]. In firefighters, a change in workload, discord at work, role conflicts, and low pride had links to depression [34]. In a previous study, 33\% of the firefighters had symptoms of depression, and firefighters who worked at the fire department had symptoms of depression 2.1 times more frequently than those who worked in the business administration department [43]. In our study, WMSD firefighters had 1.86 times more symptoms of depression then those who had not (95\%CI:1.65-2.09). 
Table 4 Adjusted odds ratio of musculoskeletal symptoms according to psychosocial factors

\begin{tabular}{|c|c|c|c|c|c|c|}
\hline \multirow[t]{3}{*}{ Job stress } & \multirow{2}{*}{\multicolumn{2}{|c|}{$\begin{array}{r}\text { Model I } \\
\text { Unadjusted } \mathrm{OR}^{*}\end{array}$}} & \multirow{2}{*}{\multicolumn{2}{|c|}{$\frac{\text { Model II }}{\text { Adjusted OR }^{\dagger}}$}} & \multirow{2}{*}{\multicolumn{2}{|c|}{$\begin{array}{r}\text { Model III } \\
\text { Adjusted OR }\end{array}$}} \\
\hline & & & & & & \\
\hline & O.R. & $95 \% \mathrm{Cl}$ & O.R. & $95 \% \mathrm{Cl}$ & O.R. & $95 \% \mathrm{Cl}$ \\
\hline \multicolumn{7}{|c|}{ Physical Environment } \\
\hline Low risk & & 1.0 & & 1.0 & & 1.0 \\
\hline High risk & 2.37 & $2.14-2.63$ & 2.31 & $2.03-2.62$ & 2.22 & $1.96-2.53$ \\
\hline \multicolumn{7}{|l|}{ Job demand } \\
\hline Low risk & & 1.0 & & 1.0 & & 1.0 \\
\hline High risk & 2.50 & $2.29-2.73$ & 1.55 & $1.38-1.74$ & 1.52 & $1.35-1.70$ \\
\hline \multicolumn{7}{|c|}{ Insufficient job control } \\
\hline Low risk & & 1.0 & & 1.0 & & 1.0 \\
\hline High risk & 1.13 & $1.02-1.25$ & 0.98 & $0.88-1.01$ & 0.99 & $0.88-1.10$ \\
\hline \multicolumn{7}{|c|}{ Interpersonal conflict } \\
\hline Low risk & & 1.0 & & 1.0 & & 1.0 \\
\hline High risk & 1.60 & $1.44-1.70$ & 1.15 & $1.03-1.29$ & 1.11 & $0.99-1.24$ \\
\hline \multicolumn{7}{|c|}{ Job insecurity } \\
\hline Low risk & & 1.0 & & 1.0 & & 1.0 \\
\hline High risk & 1.90 & $1.71-2.11$ & 1.13 & $1.02-1.25$ & 1.14 & $1.01-1.28$ \\
\hline \multicolumn{7}{|c|}{ Organizational system } \\
\hline Low risk & & 1.0 & & 1.0 & & 1.0 \\
\hline High risk & 2.22 & $2.01-2.47$ & 1.24 & $1.10-1.38$ & 1.37 & $1.21-1.56$ \\
\hline \multicolumn{7}{|c|}{ Lack of reward } \\
\hline Low risk & & 1.0 & & 1.0 & & 1.0 \\
\hline High risk & 1.92 & $1.73-2.13$ & 1.23 & $1.08-1.39$ & 1.15 & $1.01-1.31$ \\
\hline \multicolumn{7}{|c|}{ Occupational climate } \\
\hline Low risk & & 1.0 & & 1.0 & & 1.0 \\
\hline High risk & 2.16 & $1.94-2.39$ & 1.33 & $1.19-1.49$ & 1.24 & $1.11-1.40$ \\
\hline
\end{tabular}

In a previous report, the distribution of firefighter diseases included circulatory system diseases (26\%), musculoskeletal abnormalities (25\%), and psychiatric problems (16\%) [44]. The most common causes for retirement were musculoskeletal disorders (25\%), nervous system and sense organ disorders (24\%), and alimentary system problems (13\%) [44]. The prevalence of WMSDs (11\%) in male Korean firefighters was lower than in the previous study in Korea. However, musculoskeletal symptoms accounted for a significant portion of the firefighter's disabilities. Therefore the management of WMSDs are also known to be necessary for prevention in medical and engineering management and psychosocial management [45].

The limitations of this study were as follows. First, there was no physical examination or ergonomic evaluation for defining WMSDs. The personal protective equipment (self-contained breathing apparatus (SCBA), protective cloth, etc.) of a firefighter weighs just under $25 \mathrm{~kg}$, with the SCBA at about $15 \mathrm{~kg}$ [18]. We could not rule out the effect of the heavy equipment and ergonomic factor and they worked as confounding factors in our study.

Another limitation was study design. This study was a cross-sectional study, so further studies are necessary to determine the cause-effect relationship between the studied factors. In spite of these limitations, the study did evaluate enough people to represent all of the male firefighters in Korea.

\section{Conclusion}

Our result suggests that job stress may act in firefighters as a factor of WMSD development. Work to reduce job stress and a care system to mange it are needed for firefighters. 


\section{Consent}

This research was approved by the Institutional Review Board at Occupational Safety and Health Research Institute. Written informed consent was obtained from each participant prior to their involvement in the study.

\section{Competing interests}

The authors declare that they have no competing interests.

\section{Authors' contributions}

Kim K-S conceived and designed the study. All authors developed research model, especially Kim MG analyzed the statisitcs and wrote the manuscript. All authors read and approved the final manuscript.

\section{Author details}

'Department of Occupational \& Environmental Medicine, Dongguk University, Gyeongju, South Korea. ${ }^{2}$ Center for Occupational Disease Research, Occupational Safety and Health Research Institute, Korea Occupational Safety and Health Agency, Incheon, South Korea. ${ }^{3}$ Department of Preventive Medicine, School of Medicine, Kyung Hee University, Seoul, South Korea.

\section{Received: 14 February 2013 Accepted: 6 May 2013}

Published: 4 July 2013

\section{References}

1. Bogucki S, Rabinowitz PM: Occupational health of police and firefighters. In Textbook of clinical occupational and environmental medicine. 2nd edition. Edited by Rosenstock L, Cullen MR, Brodkin CA, Redlich CA. Philadelphia: Elsevier Saunders Pub; 2005:272-274.

2. Regehr C, Hill J, Glancy GD: Individual predictors of traumatic reactions in firefighters. J Nerv Ment Dis 2000, 188(6):333-339.

3. Smith DL, Manning TS, Petruzzello SJ: Effect of strenuous live-fire drills on cardiovascular and psychological responses of recruit firefighters. Ergonomics 2001, 44(3):244-254.

4. Wagner $D$, Heinrichs $M$, Ehlert U: Prevalence of symptoms of posttraumatic stress disorder in German professional firefighters. Am J Psychiatry 1998, 155(12):1727-1732.

5. Corneil W, Beaton R, Murphy S, Johnson C, Pike K: Exposure to traumatic incidents and prevalence of posttraumatic stress symptomatology in urban firefighters in two countries. J Occup Health Psychol 1999, 4(2):131-141.

6. Tornling G, Gustavsson P, Hogstedt C: Mortality and cancer incidence in Stockholm fire fighters. Am J Ind Med 1994, 25(2):219-228.

7. Lundberg U: Psychophysiology of work: stress, gender, endocrine response, and work-related upper extremity disorders. Am J Ind Med 2002, 41(5):383-392.

8. Irie M, Asami S, Nagata S, Miyata M, Kasai H: Relationships between perceived workload, stress and oxidative DNA damage. Int Arch Occup Environ Health 2001, 74(2):153-157.

9. Scott AJ: Shift work and health. Prim Care 2000, 27(4):1057-1079.

10. Bos J, Mol E, Visser B, Frings-Dresen M: Risk of health complaints and disabilities among Dutch firefighters. Int Arch Occup Environ Health 2004, 77(6):373-382.

11. Kawada T, Ooya M: Workload and health complaints in overtime workers: a survey. Arch Med Res 2005, 36(5):594-597.

12. Saijo $Y$, Ueno $T$, Hashimoto $Y$ : Job stress and depressive symptoms among Japanese firefighters. Am J Ind Med 2007, 50(6):470-480.

13. Kim JT: An analytic study on separation determinants of fireman in Pusan. Master's Dissertation. Pusan: Graduate School of Management, Pusan National University; 1991. Korean.

14. Yoo IS, Kwon SS: The present activity and job satisfaction of 119 rescuer. J Korean Soc Emerg Med 1998, 9(2):207-219. Korean.

15. Cho KY: A study on the job satisfaction of fire officials. Master's Dissertation Jinju: Graduate School of Public \& Business Administration, Gyeongsang University; 1998. Korean.

16. Dong CB: A study on duty performance of 119 rescuers. Master's Dissertation. Seoul: Graduate School of Public Administration, Kyung Hee University; 2000. Korean.
17. Park DH: A study on the prevention of safety accidents for firefighters in Korea. Master's Dissertation. Gwangju: Graduate School of Public Administration, Chonnam National University; 2003. Korean.

18. Kang SK, Kim W: Work-related musculoskeletal disorders in firefighters. Korean Med Assoc 2008, 5(12):1111-1117. Korean.

19. Kim JM, Suh BS, Kim DI, Kim WS, Cho HS, Kwon J, Yoon DY, Kim Jl, Roh YM, Jung KY, Kim JW: The study for musculoskeletal symptoms and job stress in firemen. J Korean Soc Occup Environ Hyg 2007, 17(2):111-119. Korean.

20. Saunders JB, Aasland OG, Babor TF, de la Fuente JR, Grant M: Development of the Alcohol Use Disorders Identification Test (AUDIT): WHO Collaborative Project on Early Detection of Persons with Harmful Alcohol Consumption II. Addiction 1993, 88(6):791-804.

21. Babor TF, De La Fuente JR, Saunders J, Grant M: The Alcohol Use Disorders Identification Test: Guidelines for Use in the Primary Health Care. No 894th edition. Geneva: WHO Publication; 1989.

22. Chang SJ: Standardization of job stress measurement scale for Korean employee. Incheon. Korea: OSHRI, Korea Occupational Safety and Health Agency; 2004:17-41. Korean.

23. Cho MJ, Kim KH: Diagnostic validity of the CES-D(Korean version) in the assessment of the DSM-III-R major depression. J Korean Neuropsychiatr Assoc 1993, 32(3):381-399. Korean.

24. Korea Occupational Safety and Health Agency. Guideline of harmful factors survey for musculoskeletal overloading works(KOSAH GUIDE H-9-2011). http://www.isafety.co.kr/html/law/pdf/h-09-2012.pdf. [cited May 2013].

25. Kim DS, Moon MK, Kim KS: A Survey of musculoskeletal symptoms \& risk factors for the 119 emergency medical services (EMS) activities. J Ergon Soc Korea 2010, 29(2):211-216. Korean.

26. Laursen B, Ekner D, Simonsen EB, Voigt M, Sjogaard G: Kinetics and energetics during uphill and downhill carrying of different weights. Appl Ergon 2000, 31(2):159-166.

27. Nuwayhid IA, Stewart W, Johnson JV: Work activities and the onset of first-time low back pain among New York City fire fighters. Am J Epidemiol 1993, 137(5):539-548.

28. Bonde JP, Mikkelsen S, Andersen JH, Fallentin N, Baelum J, Svendsen SW, Thomsen JF, Frost P, Kaergaard A: Understanding work related musculoskeletal pain: does repetitive work cause stress symptoms? Occup Environ Med 2005, 62(1):41-48.

29. Malchaire JB, Roquelaure $Y$, Cock N, Piette A, Vergracht S, Chiron H: Musculoskeletal complaints, functional capacity, personality and psychosocial factors. Int Arch Occup Environ Health 2001, 74(8):549-557.

30. Kim YH, Kim YT, Sun BY, Koh SB: Occupational Stress and Management Programs of Korean Female Service Professionals. Seoul: Korean Womens Development Institutes; 2006. Korean.

31. Hill J, Lewis M, Papageorgiou AC, Dziedzic K, Croft P: Predicting persistent neck pain: a 1-year follow-up of a population cohort. Spine 2004, 29(15):1648-1654.

32. Bongers PM, de Winter CR, Kompier MAJ, Hidebrandt VH: Psychosocial factors at work and musculoskeletal disease. Scand J Work Environ Health 1993, 19(5):297-312.

33. Leroux I, Brisson C, Montreuil S: Job strain and neck-shoulder symptoms: a prevalence study of women and men white-collar workers. Occup Med 2005, 56(2):102-109.

34. Lee DH, Jeon HJ, Shin DH, Chung IS, Lee MY: Association between job stress and the Minnesota multiphasic personality inventory in firefighters. Korean J Occup Environ Med 2009, 21(4):324-336.

35. Ha J, Kim DI, Seo BS, Kim WS, Ryu S, Kim SG: Jobstress and psychosocial stress among firefighters. Korean J Occup Environ Med 2008, 20(2):104-111. Korean.

36. Yoon SH, Choi SJ, Shin DH, Chung IS, Ha JS: Job stressors in subway workers and firemen. Korean J Occup Environ Med 2007, 19(3):179-186. Korean.

37. Ariens GA, Bongers PM, Douwes M, Miedema MC, Hoogendoorn WE, van der Wal G, Bouter LM, van Mechelen W: Are neck flexion, neck rotation, and sitting at work risk factors for neck pain? Results of a prospectivecohort study. Occup Environ Med 2001, 58(3):200-207.

38. Leroyer A, Edme JL, Vaxevanoglou $X$, Buisset $C$, Laurent P, Desobry P, Frimat P: Neck, shoulder, and hand and wrist pain among administrative employees: relation to work-time organization and psychosocial factors at work. J Occup Environ Med 2006, 48(3):326-333.

39. Lim HH: Job stress and depression of male industry workers. Master's Dissertation. Soowon: Graduate School of Public Health, Ajou University; 2007. Korean. 
40. Kim SY, Chang SJ, Kim HR, Rho JH: A study on the relationship between emotional labor and depressive symptoms among Korean industrial service employees. Korean J Occup Environ Med 2002, 14(3):227-235. Korean.

41. Elinson L, Houck P, Marcus SC, Pincus HA: Depression and the ability to work. Psychiatr Serv 2004, 55(1):29-34.

42. Carroll LJ, Cassidy JD, Cote P: Depression as a risk factor for onset of an episode of troublesome neck and low back pain. Pain 2004, 107(1-2):134-139.

43. Myong JP, Yim HW, Kim HR, Chae JM, Jung YK, Park Jl: Depression symptom features of an fire-station workers by job. Korean J Occup Health 2007, 46(3):85-94. Korean.

44. Szubert Z, Sobala W: Health reason for firefighter to leave their job. Med Pr 2002, 53(4):291-298.

45. Ostergren PO, Hanson BS, Balogh I, Ektor-Andersen J, Isacsson A, Orbaek P, Winkel J, Isacsson SO: Incidence of shoulder and neck pain in a working population: effect modification between mechanical and psychosocial exposures at work? Results from a one year follow up of the Malmo shoulder and neck study cohort. J Epidemiol Community Health 2005, 59(9):721-728.

doi:10.1186/2052-4374-25-9

Cite this article as: Kim et al:: Relationship between Occupational Stress and Work-related Musculoskeletal Disorders in Korean Male Firefighters. Annals of Occupational and Environmental Medicine 2013 25:9.

\section{Submit your next manuscript to BioMed Central and take full advantage of:}

- Convenient online submission

- Thorough peer review

- No space constraints or color figure charges

- Immediate publication on acceptance

- Inclusion in PubMed, CAS, Scopus and Google Scholar

- Research which is freely available for redistribution 